\title{
Attitudes of General Hospital Staff towards Persons with Mental Illness: Associations between Place of Training, Ethnicity, and Type of Profession
}

\author{
Leslie Lim ${ }^{1}$, Jeremy Heng ${ }^{1}$, Yiong-Huak Chan ${ }^{2}$ \\ ${ }^{1}$ Department of Psychiatry, Singapore General Hospital, Singapore \\ ${ }^{2}$ Biostatistics Unit, Yong Loo Lin School of Medicine, National University of Singapore, Singapore \\ Email: *leslie.lim.e.c@singhealth.com.sg
}

How to cite this paper: Lim, L., Heng, J. and Chan, Y.-H. (2020) Attitudes of General Hospital Staff towards Persons with Mental Illness: Associations between Place of Training, Ethnicity, and Type of Profession. Open Journal of Psychiatry, 10, 53-63. https://doi.org/10.4236/ojpsych.2020.102007

Received: February 6, 2020

Accepted: March 9, 2020

Published: March 12, 2020

Copyright ( 2020 by author(s) and Scientific Research Publishing Inc. This work is licensed under the Creative Commons Attribution International License (CC BY 4.0).

http://creativecommons.org/licenses/by/4.0/

(c) (i) Open Access

\begin{abstract}
Objective: Persons with mental illnesses (PMI) commonly report encountering discriminatory attitudes and behaviours by Health Care Professionals (HCPs) involved in their care. Such stigmatising attitudes and behaviours may affect recovery rates and erode quality of care provided by these HCPs. We assess attitudes of HCPs towards PMI in a tertiary general hospital in Singapore. Methods: An anonymised online questionnaire was sent to HCPs working in the hospital. Attitudes were assessed using the Opening Minds Stigma Scale for Healthcare Professionals (OMS-HC), with responses rated on a 3-point Likert scale. Results: Doctors and Chinese staff trained locally were significantly more likely to feel more comfortable treating persons with physical than psychiatric problems, whereas Indian staff were less likely to express such reservations. HCPs generally accepted physical complaints at face value, while nurses tended to adopt critical attitudes toward patients and negatively perceived the utility of psychiatric treatment. For instance, nurses were more likely to judge persons with mental illness as not trying hard enough to get better, while admitting to having difficulty feeling compassion for those with psychiatric problems. Staff who received undergraduate and postgraduate training overseas were more likely to develop favourable attitudes toward PMI. Conclusions: The study has uncovered gaps in the understanding of mental disorders and their treatment. These knowledge deficits should be rectified so as to reduce negative attitudes toward PMI.
\end{abstract}

\section{Keywords}

Attitudes, Healthcare Professionals, General Hospital 


\section{Introduction}

Many psychiatric patients report experiencing discriminatory attitudes directed at them by health care professionals (HCP) [1] [2] [3]. Some studies have even found that HCPs hold more negative attitudes toward persons with mental illness (PMI) than the general public. Such perceptions further impede recovery rates and erode quality of care provided by HCPs to these patients [4] [5].

As a result, PMI commonly report feeling devalued, dismissed, and dehumanized by many HCPs they had encountered, while others report feeling excluded from decisions, receiving subtle or overt threats of coercive treatment, being made to wait excessively long when seeking help, being given insufficient information about their condition, being treated in a paternalistic or demeaning manner, being told they would never get well, and being spoken to using stigmatizing language [6] [7] [8].

Thus, stigmatizing attitudes or behaviours may predispose to under-treatment [9] and to social marginalization [10] and can undermine the relationship between the patient and HCPs. Perhaps most importantly, stigmatizing attitudes are likely to worsen a person's feelings of rejection and isolation, thus hindering their access to appropriate care [11].

Our island nation is inhabited by a multi-ethnic, multi-cultural population of about 5.5 million persons. The main ethnic groups are the Chinese (77\%), the Malays (14\%) and the Indians (8\%) with people of other descent comprising the remaining one percent. The Chinese and Indians were immigrants from China and the Indian subcontinent respectively around the nineteenth century. The Malays were historically the earliest inhabitants, originating from Yunnan province in Southern China, and subsequently migrating south to Malaya and Singapore.

Our hospital has 1700 beds, with a staff strength comprising about 1147 doctors, 3700 nurses, and 1789 allied health professionals (AHPs). It is a teaching hospital which trains medical students and psychiatric residents and student nurses. Each month, there are approximately 230 referrals to our consultation-liaison psychiatry (CLP) service requesting assessment and management of patients suspected to be suffering from comorbid psychiatric conditions.

The present study seeks to assess attitudes toward psychiatric patients by staff in a large tertiary care hospital in Singapore. We hypothesise the presence of stigmatizing attitudes toward persons with mental illness. We expect more negative attitudes from doctors and nurses compared to allied health professionals. We hypothesise that nurses would be especially critical since they would be involved in direct patient care to a greater extent than the other two groups of HCPs.

\section{Methods}

Attitudes toward psychiatric patients were assessed using a validated rating scale. An online questionnaire was sent to all HCPs working in the hospital with re- 
sponses collected between 1 February to 30 April 2018. Staff from the departments of Psychiatry (including doctors and nurses) and Psychology were excluded from the study to avoid bias. Respondents were completely anonymised, and apart from stating their occupation e.g. doctor, nurse or allied health professional (the latter were required to state their particular vocation e.g. social worker), no other departmental details were required. The following rating scales were used to record responses from the staff. The Opening Minds Stigma Scale for Healthcare Professionals (OMS-HC) [12] and the Attitudes to Psychiatry Scale (ATP 30) with responses to the latter presented in another paper. The OMS-HC is a 15 item, self-rated scale consisting of statements to which respondents have to indicate their answer on a 5-point Likert scale, i.e. strongly disagree, disagree, neither disagree or agree, agree and strongly agree. From the 5 likely responses, we collapsed them into 3 categories, i.e. disagree, neither agree nor disagree, and agree. The OMS-HC has been shown to have acceptable internal consistency and has been successful in detecting positive changes in various anti-stigma interventions.

We obtained demographic information including age, ethnicity, gender, whether undergraduate or post graduate training was obtained, whether such training was obtained locally or overseas, whether Singapore citizen or non-citizen, and number of years worked in the hospital. The overseas countries where staff are likely to obtain training include Australia, New Zealand, United Kingdom, Ireland (including Northern Ireland, and the Republic of Ireland), Canada and the United States.

We postulated a $20 \%$ difference in stigmatising attitudes between nurses and the other health professionals. Aiming for power of $80 \%$ and 2 sided 5\%, we need to recruit at least 125 doctors, 250 nurses and 12 Allied Health staff to achieve statistical significance.

Data was analysed using the Statistical Package for the Social Sciences (SPSS) 22.0 programme with statistical significance set at $\mathrm{p}<0.05$. Pearson's chi squared or Fisher's exact tests were conducted to identify significant differences in demographic variables and responses between the doctors, nurses, and AHPs. Logistic regression was performed to adjust for relevant covariates, with odds ratios and 95\% Confidence Interval (CI) presented.

Ethical approval for the study was obtained from the hospital's Institutional Review Board.

\section{Results}

A total of 255 staff members responded to the survey, comprising 58 doctors, 130 nurses and 68 allied health professionals (AHPs). The AHPs comprised social workers, physiotherapists, occupational therapists, speech therapists and dieticians. The sociodemographic characteristics of the respondents are presented in Table 1. The Chinese were over-represented among all professional groups (being the predominant race in this country), while the Malays were over represented among nurses $(p<0.0001)$. Females out-numbered males in the nursing 
Table 1. Socio-demographic characteristics.

\begin{tabular}{|c|c|c|c|c|}
\hline & $\begin{array}{l}\text { Doctors } \\
(\mathrm{n}=58)\end{array}$ & $\begin{array}{l}\text { Nurses } \\
(\mathrm{n}=130)\end{array}$ & $\begin{array}{l}\text { Allied Health } \\
\qquad(\mathrm{n}=67)\end{array}$ & $\begin{array}{c}\chi^{2} \\
\text { p-value }\end{array}$ \\
\hline \multicolumn{5}{|c|}{ Age (years) } \\
\hline Below 29 & $18(31.9 \%)$ & $51(39.3 \%)$ & $24(35.8 \%)$ & \multirow{3}{*}{$\begin{array}{l}\chi^{2}=5.94 \\
\mathrm{P}=0.204\end{array}$} \\
\hline 30 to 49 & $33(56.9 \%)$ & $57(43.8 \%)$ & $38(56.7 \%)$ & \\
\hline $50 \&$ above & $7(12.1 \%)$ & $22(16.9 \%)$ & $5(7.5 \%)$ & \\
\hline \multicolumn{5}{|c|}{ Ethnicity } \\
\hline Chinese & $49(86.8 \%)$ & $71(54.6 \%)$ & $58(86.6 \%)$ & \multirow{4}{*}{$\begin{array}{l}\chi^{2}=7.50 \\
\mathrm{p}<0.001\end{array}$} \\
\hline Malay & $0(0.0 \%)$ & $29(22.2 \%)$ & $6(8.9 \%)$ & \\
\hline Indian & $5(7.4 \%)$ & $21(16.2 \%)$ & $2(3.0 \%)$ & \\
\hline Others & $4(5.9 \%)$ & $9(6.9 \%)$ & $1(1.5 \%)$ & \\
\hline \multicolumn{5}{|c|}{ Gender } \\
\hline Male & $29(50.0 \%)$ & $15(11.5 \%)$ & $7(10.4 \%)$ & \multirow{2}{*}{$\begin{array}{l}\chi^{2}=42.3 \\
\mathrm{p}<0.001\end{array}$} \\
\hline Female & $29(50.0 \%)$ & $115(88.5 \%)$ & $60(89.6 \%)$ & \\
\hline \multicolumn{5}{|c|}{ Working Experience (years) } \\
\hline 1 to 5 & $30(51.7 \%)$ & $36(27.7 \%)$ & $31(46.2 \%)$ & \multirow{6}{*}{$\begin{array}{l}\chi^{2}=21.4 \\
\mathrm{p}=0.018\end{array}$} \\
\hline 6 to 10 & $14(24.1 \%)$ & $42(32.3 \%)$ & $20(29.9 \%)$ & \\
\hline 11 to 15 & $4(6.9 \%)$ & $18(13.8 \%)$ & $9(13.4 \%)$ & \\
\hline 16 to 20 & $3(5.2 \%)$ & $10(7.7 \%)$ & $5(7.5 \%)$ & \\
\hline 21 to 25 & $3(5.2 \%)$ & $4(3.1 \%)$ & $1(1.5 \%)$ & \\
\hline More than 25 & $4(6.9 \%)$ & $20(15.4 \%)$ & $1(1.5 \%)$ & \\
\hline \multicolumn{5}{|c|}{ Undergraduate Studies } \\
\hline Local & $33(56.9 \%)$ & $102(78.5 \%)$ & $33(49.3 \%)$ & \multirow{3}{*}{$\begin{array}{l}\chi^{2}=55.4 \\
p<0.001\end{array}$} \\
\hline Overseas & $25(43.1 \%)$ & $10(7.7 \%)$ & $32(47.8 \%)$ & \\
\hline NA & $0(0.0 \%)$ & $18(13.8 \%)$ & $2(2.9 \%)$ & \\
\hline \multicolumn{5}{|c|}{ Postgraduate Studies } \\
\hline Local & $33(56.9 \%)$ & $70(53.8 \%)$ & $9(13.2 \%)$ & \multirow{3}{*}{$\begin{array}{l}\chi^{2}=43.2 \\
\mathrm{p}<0.001\end{array}$} \\
\hline Overseas & $6(10.3 \%)$ & $5(3.8 \%)$ & $16(23.6 \%)$ & \\
\hline NA & $19(32.8 \%)$ & $55(42.3 \%)$ & $43(63.2 \%)$ & \\
\hline
\end{tabular}

and allied health professions $(\mathrm{p}<0.001)$. The majority of doctors and AHPs reported they had up to 10 years' working experience in the hospital, whereas nurses were significantly more likely to have worked more than 20 years in the hospital $(\mathrm{p}=0.018)$.

In terms of undergraduate training, more than three quarters of the nurses were educated locally, over half the doctors and slightly less than half AHPs were educated in Singapore $\left(\chi^{2}=55.4, p<0.001\right)$. As for postgraduate training, most doctors and nurses graduated locally while AHPs were more likely to have graduated overseas $\left(\chi^{2}=43.2, \mathrm{p}=0.001\right)$. 
Responses to the following statements were rated as follows:

"I am more comfortable helping a person who has a physical illness rather than a person with a mental illness."

Doctors were significantly more likely to agree with this statement $\left(\chi^{2}=11.46\right.$, $\mathrm{p}=0.022)$. Chinese staff and those who completed their undergraduate training in Singapore were more likely to report feeling more comfortable helping patients with physical rather than mental problems $\left(\chi^{2}=13.10, \mathrm{p}=0.041 ; \chi^{2}=\right.$ $11.91, \mathrm{p}=0.018$ respectively). Conversely, Indian staff were most likely to disagree with this statement. There was no difference in response from staff who had been trained locally or overseas, and whether they had attained undergraduate or post graduate qualification (all $\mathrm{p}>0.05$ ).

"If a person with a mental illness complains of physical symptoms, I would likely attribute this to their mental illness."

There were no differences in responses among the three groups of HCPs $\left(\chi^{2}=\right.$ $7.09, \mathrm{p}=0.53)$. There were no differences in responses from staff whether they had trained locally or overseas, and whether they had attained undergraduate or post graduate qualification (all $\mathrm{p}>0.05$ ).

Similarly, no differences in responses were obtained in terms of ethnicity, number of years worked in the hospital, and citizenship status (all p > 0.05).

"More than half of the persons with mental illness don't try hard enough to get better."

As shown in Table 2, among the three groups of HCPs, the nurses were most likely to endorse such sentiments $\left(\chi^{2}=16.05, \mathrm{p}=0.003\right)$. When the ethnic groups (comprising staff from Chinese, Malay, Indian and other races) were analysed, an interesting trend emerged (see Table 2). The Malays and the other races were more likely to give a non- committal response (i.e. neither agree nor disagree), whereas the Indians and Chinese were more likely to disagree $\left(\chi^{2}=\right.$ $12.35, \mathrm{p}=0.055)$.Staff with postgraduate qualifications obtained overseas were highly likely to disagree with this statement $\left(\chi^{2}=13.04, \mathrm{p}=0.011\right)$, whereas this showed up as a trend for staff with overseas undergraduate training $\left(\chi^{2}=9.10, \mathrm{p}\right.$ $=0.058)$.

"I struggle to feel compassion for a person with mental illness."

Table 2. "More than half of people with mental illness don't try hard enough" by ethnicity.

\begin{tabular}{ccccc}
\hline Ethnic Group & $\begin{array}{c}\text { Disagree } \\
\mathrm{N}(\%)\end{array}$ & $\begin{array}{c}\text { Neither Agree nor Disagree } \\
\mathrm{N}(\%)\end{array}$ & $\begin{array}{c}\text { Agree } \\
\mathrm{N}(\%)\end{array}$ & $\begin{array}{c}\text { Total } \\
\mathrm{N}(\%)\end{array}$ \\
\hline Chinese & $101(56.7)$ & $51(28.7)$ & $26(14.6)$ & $178(100)$ \\
Malay & $15(42.9)$ & $16(45.7)$ & $4(11.4)$ & $35(100)$ \\
Indian & $17(60.7)$ & $4(14.3)$ & $7(25.0)$ & $28(100)$ \\
Other & $4(28.6)$ & $7(50.0)$ & $3(21.4)$ & $14(100)$ \\
Total & $137(53.7)$ & $78(30.6)$ & $40(15.7)$ & $255(100)$ \\
\hline
\end{tabular}

$\chi^{2}=12.35, \mathrm{p}=0.056$ 
Compared to the other professionals, nurses were more likely to agree with this statement $\left(\chi^{2}=19.36, \mathrm{p}=0.001\right)$. There were no differences in responses in terms of ethnicity, number of years worked in the hospital, and whether they were Singapore citizens or noncitizens (all p > 0.05), whereas overseas undergraduates $\left(\chi^{2}=11.19, \mathrm{df}=4, \mathrm{p}=0.024\right)$ and postgraduates $\left(\chi^{2}=12.56, \mathrm{p}=0.014\right)$ were more likely to disagree (Please refer to Table 3 ).

"There is little mental health professionals can do to help people with mental illness."

Nurses were most likely to agree with this statement $\left(\chi^{2}=14.33, \mathrm{p}=0.006\right)$, whereas doctors and AHP were most likely to disagree. Regardless of profession, those who obtained their postgraduate qualification locally were most likely to agree with this statement. Conversely, those who obtained their postgraduate qualification overseas were more likely to disagree $\left(\chi^{2}=9.559, \mathrm{p}=0.049\right)$. There was no difference in response between staff who had attained undergraduate education, whether locally or overseas $\left(\chi^{2}=3.462, \mathrm{p}=0.48\right)$. Similarly, no differences in responses were obtained in terms of ethnicity, number of years worked in the hospital and citizenship status (all p > 0.05). (Please refer to Table 4 and Table 5).

Table 3. "I struggle to feel compassion for a person with mental illness" by profession.

\begin{tabular}{ccccc}
\hline Profession & $\begin{array}{c}\text { Disagree } \\
\mathrm{N}(\%)\end{array}$ & $\begin{array}{c}\text { Neither Agree nor Disagree } \\
\mathrm{N}(\%)\end{array}$ & $\begin{array}{c}\text { Agree } \\
\mathrm{N}(\%)\end{array}$ & $\begin{array}{c}\text { Total } \\
\mathrm{N}(\%)\end{array}$ \\
\hline Doctor & $45(77.6)$ & $3(5.2)$ & $10(17.2)$ & $58(100)$ \\
Nurse & $67(51.5)$ & $29(22.3)$ & $34(26.2)$ & $130(100)$ \\
Allied Health & $51(76.1)$ & $7(10.4)$ & $9(13.4)$ & $67(100)$ \\
\hline
\end{tabular}

$\chi^{2}=19.36 \mathrm{p}=0.001$

Table 4. "There is little mental health professionals can do to help PMI" by profession.

\begin{tabular}{ccccc}
\hline Profession & $\begin{array}{c}\text { Disagree } \\
\mathrm{N}(\%)\end{array}$ & $\begin{array}{c}\text { Neither Agree nor Disagree } \\
\mathrm{N}(\%)\end{array}$ & $\begin{array}{c}\text { Agree } \\
\mathrm{N}(\%)\end{array}$ & $\begin{array}{c}\text { Total } \\
\mathrm{N}(\%)\end{array}$ \\
\hline Doctor & $39(67.2)$ & $11(19.0)$ & $8(13.8)$ & $58(100)$ \\
Nurse & $66(50.8)$ & $29(22.3)$ & $35(26.9)$ & $130(100)$ \\
Allied Health & $51(76.1)$ & $6(9.0)$ & $10(14.9)$ & $67(100)$ \\
\hline
\end{tabular}

$\chi^{2}=14.33, \mathrm{p}=0.006$

Table 5. "There is little mental health professionals can do to help PMI" by place of undergraduate training.

\begin{tabular}{ccccc}
\hline $\begin{array}{c}\text { Place of } \\
\text { Undergraduate training }\end{array}$ & $\begin{array}{c}\text { Disagree } \\
\mathrm{N}(\%)\end{array}$ & $\begin{array}{c}\text { Neither Agree nor Disagree } \\
\mathrm{N}(\%)\end{array}$ & $\begin{array}{c}\text { Agree } \\
\mathrm{N}(\%)\end{array}$ & $\begin{array}{c}\text { Total } \\
\mathrm{N}(\%)\end{array}$ \\
\hline Local & $99(58.9)$ & $32(19.0)$ & $37(22.1)$ & $58(100)$ \\
Overseas & $53(79.1)$ & $3(4.5)$ & $11(16.4)$ & $67(100)$ \\
NA & $11(76.1)$ & $4(9.0)$ & $5(14.9)$ & $20(100)$
\end{tabular}

NA: not applicable. $\chi^{2}=11.19, \mathrm{p}=0.024$. 


\section{Discussion}

There were distinct differences in responses between various professionals to the questions posed, with doctors and AHPs likely to respond in a similar fashion. There were also differences in responses between ethnic groups, whether they were locally or overseas trained, and the type of profession they belonged to. Doctors, by virtue of their training in physical medicine, expressed greater confidence in handling patients with physical disorders as opposed to psychiatric disorders.

Compared to the other ethnic groups, Indian staff seemed most comfortable in handling patients with psychiatric disorders in addition to those with medical conditions. This is somewhat surprising since the majority of the patients and staff were of Chinese ethnicity, with Indians in the minority. Being a general hospital, unsurprisingly most staff were trained to manage patients with medical rather than psychiatric problems.

There is the belief that physical symptoms voiced by patients with a psychiatric diagnosis are not taken seriously, and that these symptoms are by-products of their psychiatric conditions.

Persons with mental illnesses commonly report barriers to having their physical care needs met, including not having their symptoms taken seriously when seeking care for non mental health concerns [6] [8] whereby physical symptoms are misattributed to a patient's mental illness [13]. Some have observed that persons with mental illness histories receive poorer quality care for their physical health problems [13]. Our findings run contrary to this notion, with HCPs accepting physical symptoms at face value, much to their credit. Being a tertiary care teaching hospital, we have the technology and expertise to fully investigate and treat any physical condition should these be discovered. In the face of increasing potential litigiousness among the general population, there is a tendency to practise defensively for fear of missing some genuine physical pathology. Hence physical symptoms are usually taken seriously and are thoroughly investigated.

Among HCPs, only nurses seemed to view mental health professionals as being less than able to help patients with psychiatric problems. This probably represents deficiencies in local nurse training with perhaps a lack of exposure to psychiatric nursing. The vast majority of nurses had not worked in a mental health setting, and have been trained to look after patients with physical problems. Exposure to postgraduate training overseas seemed to have conferred added benefit, enabling staff to acquire mental health literacy-both understanding illness aetiology and treatment-while developing compassion toward PMI.

It is well reported that healthcare professionals tend to hold pessimistic views about the reality and likelihood of recovery of persons experiencing psychiatric disorders [14] [15] [16]. Research also suggests that pessimism about recovery for some HCPs is associated with a sense of helplessness, leading them to believe that "what they do doesn't matter" [17]. 
Our study has also uncovered certain critical attitudes toward psychiatric patients. There is the perception that psychiatric patients are not trying hard enough. This again is a reflection of insufficient mental health literacy. It is a common lay perception that psychiatric problems are the result of a lack of will power, with some advising PMI to "pull yourself together" as if that will somehow make psychiatric disorders go away.

Critical attitudes by nurses toward psychiatric patients are not uncommon as demonstrated by a fairly recent study in Kuwait [18]. Also, patients with certain disorders, such as personality disorders, tend to be particularly rejected by healthcare staff and are often felt to be difficult, manipulative, and less deserving of care [19] [20].

These negative attitudes may have arisen as a result of poor skills [13] [19]. Conversely, nurses with higher education and those exposed to specialized psychiatric training showed more positive attitudes than unqualified staff and those without any psychiatric training [1] [21] [22].

The view that mental health literacy is lacking among certain categories of HCP is supported by our finding that staff with postgraduate qualifications are more likely to dismiss these erroneous beliefs. Presumably, with better levels of mental health literacy, staff should harbour less critical perceptions toward PMI. Indeed, exposure to a psychiatric setting during training and having personal contact with PMI have both been associated with positive attitudes [23] [24] [25] [26] [27], although other researchers have found no such associations [28] [29] [30].

Our study has several strengths and limitations worth mentioning. In regards limitations, there was a low response rate. Not all staff have access to emails at work. For instance, lower ranked nursing staff and some AHPs may not have email accounts at work and hence might not have had a chance to participate in the study. Conversely, the more senior staff had email accounts and were more likely to hold positions of responsibility, hence their perceptions would be of great value to our study.

The views of the study cohort might not truly reflect the attitudes and perceptions of the entire staff population. Moreover, it is impossible to predict whether staff with positive attitudes toward PMI would be more or less likely to participate in the study.

Notwithstanding limitations, our study has certain strengths. Responses were completely anonymised such that any information could not be traceable to the individual respondents or to the departments they represented. With this assurance of complete anonymity, responses could be as candid as possible. Nevertheless, we have recruited a sizeable number of HCPs of various ages, ethnicity, grades and experience levels to enable meaningful analysis of their responses.

\section{Conclusions}

The study has uncovered gaps in understanding of mental disorders and their treatment. It is likely that critical attitudes were formed as a result of ignorance 
and insufficient exposure to mental disorders and their treatments. These knowledge deficits should be addressed through skills training, in-service talks, case discussions and the like, so that HCPs will not only become more competent in handling these patients, but also develop compassion for those under their care. Notwithstanding the sentiments expressed, it is worthwhile noting that physical symptoms are likely to be taken seriously and not merely attributed to psychosomatic aetiologies.

Conversely, our findings suggest that staff who received undergraduate and postgraduate training overseas were more likely to develop favourable attitudes toward PMIs. This serves as an endorsement of the quality of overseas undergraduate and postgraduate training in not only embracing the biological but also inculcating a holistic appraisal of the psychosocial needs of patients as well. Qualitative research has found that for many HCPs, it is only through the experience of receiving anti-stigma training that they become aware of the subtle and unintended ways certain beliefs and behaviours may have contributed to stigmatizing experiences felt by their patients [17] [31] [32]. Any training should lay emphasis to the fact that recovery from a mental illness is possible, while demonstrating how HCPs can contribute to patients' recovery from their mental conditions [33].

\section{Conflicts of Interest}

The authors declare no conflicts of interest regarding the publication of this paper.

\section{References}

[1] Brinn, F. (2000) Patients with Mental Illness: General Nurses' Attitudes and Expectations. Nursing Standard, 14, 32-36. https://doi.org/10.7748/ns2000.03.14.27.32.c2792

[2] Schulze, B. and Angermeyer, M.C. (2003) Subjective Experiences of Stigma. A Focus Group Study of Schizophrenic Patients, Their Relatives and Mental Health Professionals. Social Science and Medicine, 56, 299-312. https://doi.org/10.1016/S0277-9536(02)00028-X

[3] Nordt, C., Anthony, M., Ajdacic-Gross, V. and Rössler, W. (2004) What about Psychiatrists' Attitudes to Mentally Ill People. European Psychiatry, 19, 423-427. https://doi.org/10.1016/j.eurpsy.2004.06.019

[4] Jorm, A.F., Korten, A.E., Jacomb, P.A., Christensen, H. and Henderson, S. (1999) Attitudes towards People with a Mental Disorder: A Survey of the Australian Public and Health Professionals. Australian New Zealand Journal of Psychiatry, 33, 77-83. https://doi.org/10.1046/j.1440-1614.1999.00513.x

[5] Chambers, M., Guise, V., Välimäki, M., Botelho, M.A., Scott, A., Staniuliené, V., et al. (2010) Nurses' Attitudes to Mental Illness: A Comparison of a Sample of Nurses from Five European Countries. International Journal of Nursing Studies, 47, 350-362. https://doi.org/10.1016/j.ijnurstu.2009.08.008

[6] Hamilton, S., Pinfold, V., Cotney, J., et al. (2016) Qualitative Analysis of Mental Health Service Users' Reported Experiences of Discrimination. Acta Psychiatrica Scandinavica, 134, 14-22. https://doi.org/10.1111/acps.12611 
[7] Thornicroft, G., Rose, D. and Mehta, N. (2010) Discrimination against People with Mental Illness: What Can Psychiatrists Do? Advances in Psychiatric Treatment, 16, 53-59. https://doi.org/10.1192/apt.bp.107.004481

[8] Clark, D., Dusome, D. and Hughes, L. (2007) Emergency Department from the Mental Health Client's Perspective. International Journal of Mental Health Nursing, 16, 126-131. https://doi.org/10.1111/j.1447-0349.2007.00455.x

[9] Oliver, M. and Pearson, N. (2005) Help-Seeking Behaviour in Men and Women with Common Mental Health Problems: Cross-Sectional Study. British Journal of Psychiatry, 186, 297-301. https://doi.org/10.1192/bjp.186.4.297

[10] Thornicroft, G. (2008) Stigma and Discrimination Limit Access to Mental Health Care. Epidemiologia e Psichiatria Sociale, 17, 14-19. https://doi.org/10.1017/S1121189X00002621

[11] Corrigan, P. (2004) How Stigma Interferes with Mental Health Care. American Psychologist, 59, 614-625. https://doi.org/10.1037/0003-066X.59.7.614

[12] Modgill, G., Patten, S.B., Knaak, S., et al. (2014) Opening Minds Stigma Scale for Health Care Providers (OMS-HC): Examination of Psychometric Properties and Responsiveness. BMC Psychiatry, 14, Article No. 120.

https://doi.org/10.1186/1471-244X-14-12

[13] Jones, S., Howard, L. and Thornicroft, G. (2008) Diagnostic Overshadowing: Worse Physical Care for People with Mental Illness. Acta Psychiatrica Scandinavica, 118, 169-171. https://doi.org/10.1111/j.1600-0447.2008.01211.x

[14] Henderson, C., Noblett, J., Parke, H., et al. (2014) Mental Health-Related Stigma in Healthcare and Mental Health-Care Settings. Lancet Psychiatry, 1, 467-482. https://doi.org/10.1016/S2215-0366(14)00023-6

[15] Schulze, B. (2007) Stigma and Mental Health Professionals: A Review of the Evidence on an Intricate Relationship. International Review of Psychiatry, 19, 137-155. https://doi.org/10.1080/09540260701278929

[16] Corrigan, P., Druss, B. and Perlick, D. (2014) The Impact of Mental Illness Stigma on Seeking and Participating in Mental Health Care. Psychological Science in the Public Interest, 15, 37-70. https://doi.org/10.1177/1529100614531398

[17] Knaak, S. and Patten, S. (2016) A Grounded Theory Model for Reducing Stigma in Health Professionals in Canada. Acta Psychiatrica Scandinavica, 134, 53-62. https://doi.org/10.1111/acps.12612

[18] Al-Awadhi, A., Atawneh, F., Alalyan, M.Y., Shahid, A.A., Al-Alkhadhari, S. and Zahid, M.A. (2017) Nurses' Attitude towards Patients with Mental Illness in a General Hospital in Kuwait. Saudi Journal of Medicine and Medical Science, 5, 31-37. https://doi.org/10.4103/1658-631X.194249

[19] Ross, C. and Goldner, E. (2009) Stigma, Negative Attitudes and Discrimination towards Mental Illness within the Nursing Profession: A Review of the Literature. Journal of Psychiatric Mental Health Nursing, 16, 558-567. https://doi.org/10.1111/j.1365-2850.2009.01399.x

[20] Knaak, S., Szeto, A.C.H., Fitch, K., Modgill, G. and Patten, S. (2015) Stigma towards Borderline Personality Disorder: Effectiveness and Generalizability of an Anti-Stigma Program for Healthcare Providers Using a Pre-Post Randomized Design. Borderline Personality Disorder Emotion Dysregulation, 2, 9. https://doi.org/10.1186/s40479-015-0030-0

[21] Scott, D.J. and Philip, A.E. (1985) Attitudes of Psychiatric Nurses to Treatment and Patients. British Journal of Medical Psychology, 58, 169-173. https://doi.org/10.1111/j.2044-8341.1985.tb02630.x 
[22] Mavundla, T.R. and Uys, L.R. (1997) The Attitudes of Nurses' Mobility in Europe: A Case for Language Skills. Nurse Education Today, 17, 87-90. https://doi.org/10.1016/S0260-6917(97)80023-8

[23] Read, J. and Law, A. (1999) The Relationship of Causal Beliefs and Contact with Users of Mental Health Services to Attitudes to the "Mentally Ill". International Journal of Social Psychiatry, 45, 216-229. https://doi.org/10.1177/002076409904500309

[24] Couture, S.M. and Penn, D.L. (2003) Interpersonal Contact and the Stigma of Mental Illness: A Review of the Literature. Journal of Mental Health, 12, 291-305. https://doi.org/10.1080/09638231000118276

[25] Fujii, T., Hanya, M., Kishi, M., Kondo, Y., Cates, M.E. and Kamei, H. (2018) An Internet-Based Survey in Japan Concerning Social Distance and Stigmatization toward the Mentally Ill among Doctors, Nurses, Pharmacists, and the General Public. Asian Journal of Psychiatry, 36, 1-7. https://doi.org/10.1016/j.ajp.2018.05.017

[26] Bairan, A. and Farnsworth, B. (1989) Attitudes toward Mental Illness: Does a Psychiatric Nursing Course Make a Difference? Archives of Psychiatric Nursing, 3, 351-357.

[27] McLaughlin, C. (1997) The Effect of Classroom Theory and Contact with Patients on the Attitudes of Student Nurses towards Mentally Ill People. Journal of Advanced Nursing, 26, 1221-1228. https://doi.org/10.1111/j.1365-2648.1997.tb00816.x

[28] Weller, L. and Grunes, S. (1988) Does Contact with the Mentally Ill Affect Nurses' Attitudes to Mental Illness? British Journal of Medical Psychology, 61, 277-284. https://doi.org/10.1111/j.2044-8341.1988.tb02789.x

[29] Callaghan, P., Shan, C.S., Yu, L.S., Ching, L.W. and Kwan, T.L. (1997) Attitudes towards Mental Illness: Testing the Contact Hypothesis among Chinese Student Nurses in Hong Kong. Journal of Advanced Nursing, 26, 33-40. https://doi.org/10.1046/j.1365-2648.1997.1997026033.x

[30] Aydin, N., Yigit, A., Inandi, T. and Kirpinar, I. (2003) Attitudes of Hospital Staff toward Mentally Ill Patients in a Teaching Hospital, Turkey. International Journal of Social Psychiatry, 49, 17-26. https://doi.org/10.1177/0020764003049001544

[31] Sukhera, J. and Chahine, S. (2016) Reducing Mental Illness Stigma through Unconscious Bias-Informed Education. MedEdPublish, 5, 16. https://doi.org/10.15694/mep.2016.000044

[32] Horsfall, J., Cleary, M. and Hunt, G. (2010) Stigma in Mental Health: Clients and Professionals. Issues in Mental Health Nursing, 31, 450-455. https://doi.org/10.3109/01612840903537167

[33] Knaak, S., Modgill, G. and Patten, S. (2014) Key Ingredients of Anti-Stigma Programs for Health Care Providers: A Data Synthesis of Evaluative Studies. The Canadian Journal of Psychiatry, 59, S19-S28.

https://doi.org/10.1177/070674371405901S06 